\title{
Voltage attenuation in reconstructed type-identified motor neurons as a constraint for reduced models Hojeong Kim ${ }^{1}$, Lora A Major ${ }^{2}$ and Kelvin E Jones*1,2
}

Address: ${ }^{1}$ Department of Biomedical Engineering, University of Alberta, Edmonton, Canada, T6G 2V2 and ${ }^{2}$ Faculty of Physical Education and Recreation, University of Alberta, Edmonton, Canada, T6G 2H9

Email: Kelvin E Jones* - kelvin.jones@ualberta.ca

* Corresponding author

from Seventeenth Annual Computational Neuroscience Meeting: CNS*2008 Portland, OR, USA. 19-24 July 2008

Published: II July 2008

BMC Neuroscience 2008, 9(Suppl I):P55 doi: I0.1 186/I47I-2202-9-SI-P55

This abstract is available from: http://www.biomedcentral.com/I47I-2202/9/SI/P55

(c) 2008 Kim et al; licensee BioMed Central Ltd.

\section{Introduction}

Attenuation of voltage in dendrites depends on the direction of propagation [1]: Direction Dependent Voltage Attenuation (DDVA). This study's objectives were to: 1) determine whether DDVA differed for motor neurons of different types (i.e. slow - fast), and 2) derive the cable parameters for reduced models that satisfy DDVA for the heteronymous properties of motor neurons in a pool.

\section{Methods}

The morphologies of six type-identified cat spinal motor neurons were downloaded from a public database [2] and imported into the NEURON simulation environment. Passive parameters were set to experimentally determined values from these same cells [3]. DDVA was characterized by calculating the voltage attenuation between the soma and all sites on the dendrites in both directions.

\section{Results}

Voltage attenuation changed rapidly with distance from the soma for central propagation (Fig 1 left) compared to the peripheral direction (Fig 1 right). The change in voltage attenuation with distance was well described by a single exponential function, fitting a voltage decay constant (VDC). A comparison of VDCs for S, FR and FF-type motor neurons did not reveal significant differences resulting from type-specific morphology. The input resistance of the six anatomical models was varied from $0.4-$ 4.0 MOhm by changing passive parameters. All models had similar monotonic relationships between input resist- ance and VDC. These results were used to derive two-compartment models in which all cable parameters could be determined analytically by specifying the parameters of input resistance and distance between soma and dendrite compartments.

\section{Discussion}

Type-specific dendritic morphology had no obvious effect on DDVA. DDVA in spinal motor neurons was fully characterized by input resistance at the soma. The two-compartment models are the first to analytically solve for reduced cable parameters based on reconstructed neurons. This solution has important implications for the bistable firing behavior in these cells.
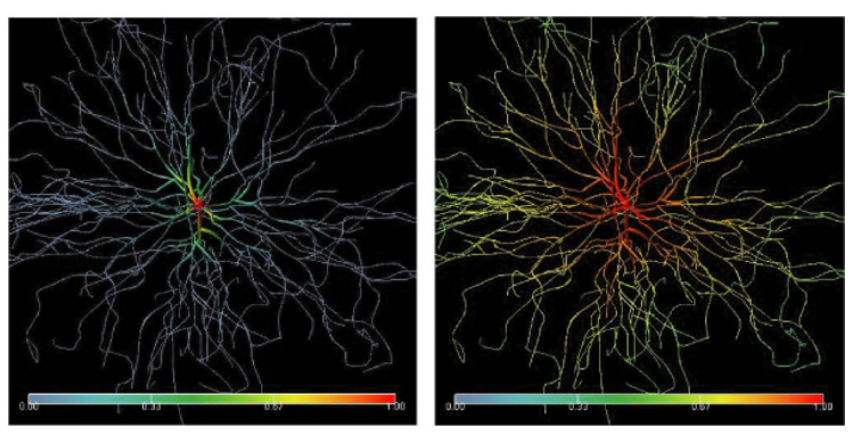

Figure I

DDVA in an adult cat spinal cord motor neuron. 


\section{Acknowledgements}

Work supported by grants from NSERC and AHFMR.

\section{References}

I. Rall W, Rinzel J: Branch input resistance and steady attenuation for input to one branch of a dendritic neuron model. Biophys J 1973, I 3:648-687.

2. Ascoli GA, Donohue DE, Halavi M: NeuroMorpho.Org: a central resource for neuronal morphologies. J Neurosci 2007, 27:9247-925I.

3. Fleshman JW, Segev I, Burke RB: Electrotonic architecture of type-identified alpha-motoneurons in the cat spinal cord. J Neurophysiol 1988, 60:60-85.

Publish with BioMed Central and every scientist can read your work free of charge

"BioMed Central will be the most significant development for disseminating the results of biomedical research in our lifetime. "

Sir Paul Nurse, Cancer Research UK

Your research papers will be:

- available free of charge to the entire biomedical community

- peer reviewed and published immediately upon acceptance

- cited in PubMed and archived on PubMed Central

- yours - you keep the copyright 